Acta Psychologica 31 (1969) 194-196; (C) North-Holland Publishing Co., Amsterdam Not to be reproduced in any form sitinut writter permission from the pubis her

\title{
A THEORY OF THE HUMAN PERSON AND ITS WORLD
}

\author{
M. J. L,ANGEVELD \\ Paedagogisch Instituut, Trans 14, Utrecht, The Netheriands
}

Professor Hans Thomae (Bonn, Germany) has recently published a work which deserves the attention of the psychological world. ${ }^{1}$ For though thare are many books on personality, few are as original, as well doctimented and based on so many investigations done by the author himself, while at the same time the longitudinal aspect o: this study offers an overall view of human personality in its development through different periods of life.

The book addresses itself to the scholarly reader with an interest in the experimental approach who is inclined to consider difficult problems in his own field as well as in philosophy of the human person.

'Human difference' is Thomae's first and is Thomae's last vord. In his Preface he remarks that all too often the clinical applied psychologist of our days is inclined to overlook the fact that psychology has taken its origin also in this question of human difference. If, however, such a psychologist - Thomae says - would take his practical occupation with the individual characteristics of human needs too seriously, he is risking nowadays that his 'scientifically' occupied colleagues would not take him too seriously. They are then conforming themselves to the general bias to generalisation and levelling and they satisfy themselves like their academic examples, Thomae continues - with some lip-service to the idea of individuality. And when the author arrives at the end of fis book he speaks about the different subjective ideas of what is meaningful to a person. He then concludes - and ends his book - with the question whether psychology, as it has been inclined to 'adjust' the individual to seciety over the last fifty years, might not be confronted now more strongly with the reversed question: how society could be adapted to the difference of individual worlds of meaning.

However this may be: these two statements characterize at least the individuality of an author and of a fascinating book.

t 'Das Individuum und seine Welt. Eine Persorlichkeitstheor e' is published by Hogrefe, Göttingen (Germany) 1968, with 589 pages of text, a bibliography of another 46 pages and 24 pages of indexes. 
As Thomae is a Germa he knows the Gernan tradition very well (he dedicates his book to Philipp' Lersch), but he is particularly well versed in the Americar literature concerning his subject. Sorne English, Russi:n tut few Frerch or sources in other la aguages are being consulteà.

His book is composed of three main parts. Part I gives an introductory survey of the study of personality in the psychology of today. Part II develops the methodology and system of a psychology of the individual. Part III treats the principles of the creating and structuring of personal iferticy and continuity. The book concludes with a paragraph about the problem of self, the experience of the self and of oneself as a historical order of facts and events.

When w/e look at the book of this size, level and complexity it takes another bool: to analyse it and consequently we can discuss only a few aspects of it.

First of all it is a sign of the mature researcher that Thomae is very reserved in his appreciation of the results and consequences of what are supposed to be highly exact methods. All too often they produce meagre, misleading or simply erroneous esults in terms of human reality. As a well-qualified and experienced psychological researcher he is not simply taken in by the formalising characteristic of such an appioach. But also where Thomae discusses the structure of theories e.g. Goldstein's, Maslow's, Eysenck's etc. - he shows a strong sense of reality. At the same time Thomae is far from being, a 'speculative' thinker. On the contrary. Where the weakness might reside in a lack of clear analysis and adequate methodoiogical control Thomae will prove his immediate alertness. This becomes particularly evident in his second part (On the methodology and system of a psychology of the individual). where he analyses the basic categories of psychological biography (p. 124-216) and in the highly interesting development of motivation, human patterns of concern and the thematic structure of meaningfulness in the life of people. A wealth of material from different perio's of life, particularly from adulthood, is brought into a number of most relevant patterns of life-situations. Here the cuthor's deas are often see $i$ in connection with those of Cantril.

Oi particular interest is the way in which Thomae treats of the "cirronification' - the becoming 'chronic' - of certair 'leading melodies' in a human person's life. When he describes 'chronification' he start., from situationally conditioned, temporary structuring as opposed to the 
stiucture formation of a long lasting if not permanent character. Here again Thomae's own studies of a longitudinal character are most helpful in gradually bringing out the picture of an individual's 'vorld', his horizon of life conditioned by his life experiences, etc. and creating a 'Lebensraum', a universe of mea ling predominantly meaningful to this person as a set of conditions and concerns within which he is realizing his life. The relation to the future, the prospective attitude is here a story in itself as well as the role of shildhood, its after-effects in attitu $s$ and accepted roles and rules. In this frame of reference the importance of the 'ch:onification' of experiences and attitudes conditioned by them sppears vary clearly again.

From this total pattern it is now possible to understand or rephrase many ideas and practices in present-day developmental psychology as well as in e.g., psycho-analytic interpretation and therapy.

NOTE

Note on: 'New directions for theory and research on rule learning. III. Analyses and theoretical direction', by Joseph M. Scandura. Vol. 29, no. 3, p. 216.

The author has recently worked out a more rigorous approach to the problem of 'What is learned' than is given in this section, and those wishing to make reference to it are asked to contact him for a statement of his latest position. 